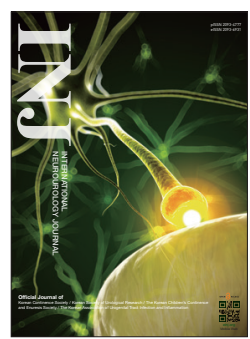

\title{
Therapeutic Strategies Against Apoptosis and Gliosis
}

\author{
Il-Gyu Ko (iD https://orcid.org/0000-0003-2696-6869 \\ Department of Physiology, College of Medicine, Kyung Hee University, Seoul, Korea \\ E-mail: rhdlfrb@hanmail.net
}

This special issue of the International Neurourology Journal has recruited articles on the subject of "Therapeutic Strategies Against Apoptosis and Gliosis." Apoptosis, also referred to as programmed cell death, is a mechanism in biology by which cells self-destruct when stimulated by appropriate triggers. Apoptosis differs from another major cell death process, known as necrosis. Apoptosis involves dividing cells into well-defined pieces for condensation and disposal of the nucleus and cytoplasm. Many diseases and disorders are associated with the life and death of cells. Increased cell death is characteristic of AIDS, Alzheimer disease, and Parkinson disease, and reduced cell death may occur in lupus or cancer. Gliosis refers to nonspecific changes in glial cells in response to damage to the central nervous system. In most cases, gliosis involves the proliferation or hypertrophy of several different types of glial cells, including astrocytes, microglia, and oligodendrocytes.

Kim [1] wrote a review paper on voiding dysfunction and apoptosis in the detrusor muscle. Increased apoptosis was observed in both detrusor hyperactivity and detrusor hypoactivity. Nevertheless, it was concluded that research on the role of apoptosis of the detrusor muscle in voiding disorder is limited. Corujo-Ramirez et al. [2] reported that BubR1 hypomorphic $\left(B u b R 1^{\mathrm{H} / \mathrm{H}}\right)$ mice had a significantly increased level of astrogliosis and an increased tendency to activate microglial cells in the young adult hippocampus, indicating that BubR1 insufficiency accelerates glial reactivity. Genetic inhibition of secreted frizzled related protein 3 (sFRP3) significantly restored the astrogliosis and microglial activation observed in $B u b R 1^{\mathrm{H} / \mathrm{H}}$ mice, suggesting that sFRP3 plays an important neuroprotective role in agerelated neuroinflammation. Two papers in this special issue deal with the antiapoptotic effects of polydeoxyribonucleotide
(PDRN). Rho et al. [3] studied the effect of PDRN on inflammation and apoptosis in rats with Achilles tendon injury. They found that PDRN treatment reduced the percentages of cleaved caspase-3-positive cells and caspase-9-positive cells and diminished the Bcl-2-associated X protein (Bax) to B-cell lymphoma 2 (Bcl-2) ratio in rats with Achilles tendon injuries. Therefore, PDRN may be a novel treatment for Achilles tendon injury through its anti-inflammatory and anti-apoptotic effects. Lee et al. [4] evaluated the effect of PDRN treatment on carbon tetrachloride $\left(\mathrm{CCl}_{4}\right)$-induced acute liver injury (ALI) using mice. $\mathrm{PDRN}$ injection reduced the $\mathrm{Bax}$ to $\mathrm{Bcl}-2$ ratio and the percentage of terminal deoxynucleotidyl transferase-mediated dUTP nick end labeling (TUNEL)-positive cells in $\mathrm{CCl}_{4}$-induced ALI mice. They concluded that PDRN could be used as a treatment for $\mathrm{CCl}_{4}$-induced ALI. Ko and Ko [5] investigated the effect of voluntary wheel running on brain inflammation in rats in relation to inflammation and apoptosis. Voluntary wheel running after brain inflammation improved spatial learning memory by inhibiting pro-inflammatory cytokine production and apoptotic cell death. Cho et al. [6] demonstrated that a phosphatase and tensin homologue (PTEN) inhibitor was effective for restoring voiding efficiency and motor function after spinal cord injury.

Apoptosis is one of the most important topics in medicine and biology. The development of treatments to prevent apoptosis in the bladder, urethra, and kidneys may be a target for the treatment of many urogenital disorders. We have recruited the papers in this special issue to overcome extant limitations in urology treatment and to obtain insights into other diseases. Through this issue, we will continue our efforts to identify new 
treatment technologies and mechanisms for urological diseases. On behalf of the editorial board, I am deeply grateful to the authors for submitting these superb articles.

- Conflict of Interest: No potential conflict of interest relevant to this article was reported.

\section{REFERENCES}

1. Kim SJ. The role of apoptosis in detrusor contractility. Int Neurourol J 2020;24(Suppl 2):S67-71.

2. Corujo-Ramirez AM, Dua N, Yoo KH, Oliveros A, Jang MH. Genetic inhibition of $s F R P 3$ prevents glial reactivity in a mouse model of accelerated aging. Int Neurourol J 2020;24(Suppl 2):S72-8.
3. Rho JH, Ko IG, Jin JJ, Hwang L, Kim SH, Chung JY, et al. Polydeoxyribonucleotide ameliorates inflammation and apoptosis in Achilles tendon-injury rats. Int Neurourol J 2020;24(Suppl 2):S79-87.

4. Lee S, Won KY, Joo S. Protective effect of polydeoxyribonucleotide against CCl4-induced acute liver injury in mice. Int Neurourol J 2020;24(Suppl 2):S88-95.

5. Ko YJ, Ko IG. Voluntary wheel running improves spatial learning memory by suppressing inflammation and apoptosis via inactivation of nuclear factor kappa B in brain inflammation rats. Int Neurourol J 2020;24(Suppl 2):S96-103.

6. Cho YS, Kim SJ, Kim KH. Evaluation of PTEN inhibitor following spinal cord injury on the recovery of voiding efficiency and motor function observed by regeneration in spinal cord. Int Neurourol J 2020;24(Suppl 2):S104-10. 